\title{
Bacterial Cellulose As a Support for the Growth of Retinal Pigment Epithelium
}

Sara Gonçalves, ${ }^{\dagger}$ Jorge Padrão, ${ }^{\dagger}$ Inês Patrício Rodrigues, ${ }^{\ddagger}, \S$ João Pedro Silva, ${ }^{\dagger}$ Vítor Sencadas, ${ }^{\dagger}$ Senentxu Lanceros-Mendez, " Henrique Girão, ${ }^{\ddagger}$ Fernando Dourado, ${ }^{\dagger}$ and Lígia R. Rodrigues ${ }^{*} \dagger$

${ }^{\dagger}$ Centre of Biological Engineering and "Center/Department of Physics, University of Minho, Campus de Gualtar, 4710-057, Braga, Portugal

${ }^{\ddagger}$ Centre of Ophthalmology and Vision Sciences, IBILI-Faculty of Medicine, University of Coimbra, 3000-354, Coimbra, Portugal

${ }^{\S} \mathrm{CNC}$ - Center for Neuroscience and Cell Biology, University of Coimbra, 3004-517, Coimbra, Portugal

Supporting Information

ABSTRACT: The feasibility of bacterial cellulose (BC) as a novel substrate for retinal pigment epithelium (RPE) culture was evaluated. Thin ( $41.6 \pm 2.2 \mu \mathrm{m}$ of average thickness) and heat-dried BC substrates were surface-modified via acetylation and polysaccharide adsorption, using chitosan and carboxymethyl cellulose. All substrates were characterized according to their surface chemistry, wettability, energy, topography, and also regarding their permeability, dimensional stability, mechanical properties, and endotoxin content. Then, their

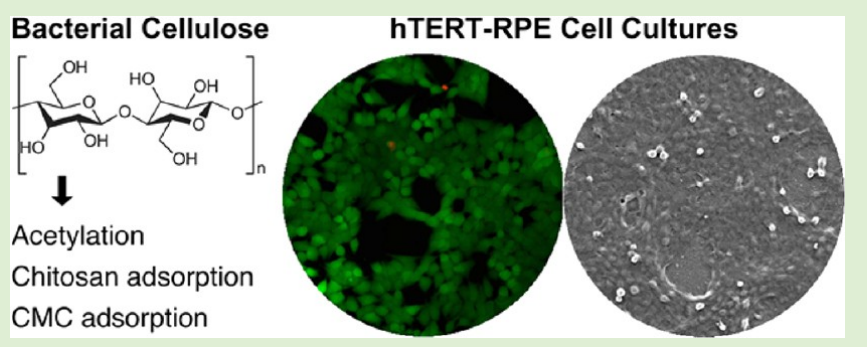
ability to promote RPE cell adhesion and proliferation in vitro was assessed. All surface-modified BC substrates presented similar permeation coefficients with solutes of up to $300 \mathrm{kDa}$. Acetylation of $\mathrm{BC}$ decreased it's swelling and the amount of endotoxins. Surface modification of BC greatly enhanced the adhesion and proliferation of RPE cells. All samples showed similar stress-strain behavior; BC and acetylated BC showed the highest elastic modulus, but the latter exhibited a slightly smaller tensile strength and elongation at break as compared to pristine BC. Although similar proliferation rates were observed among the modified substrates, the acetylated ones showed higher initial cell adhesion. This difference may be mainly due to the moderately hydrophilic surface obtained after acetylation.

\section{INTRODUCTION}

Age-related macular degeneration (AMD) is a leading cause of irreversible blindness among the elderly in industrialized countries, and its cure is of increasing socioeconomic interest within the progressive demographic right-shift. ${ }^{1-4}$ This disease affects the retinal pigment epithelium (RPE), the Bruch's membrane (BM), and the choroid, consequently leading to the damage of the photoreceptors. ${ }^{1,2}$ The RPE constitutes the outer blood-retina barrier, preventing the transport of molecules larger than $300 \mathrm{kDa}$ into and out of the retina. ${ }^{5,6}$ Apically facing the photoreceptors and basolaterally the BM, RPE is a cell monolayer responsible for several complex functions essential for the visual function. ${ }^{5}$ Located between the RPE and the fenestrated choriocapillaries, the BM is an extracellular matrix structure composed of elastin and collagen that partly regulates the reciprocal exchange of biomolecules, nutrients, oxygen, fluids, and metabolic waste products between the retina and the general circulation. ${ }^{6}$ When the RPE cells are lost and the BM is compromised in retinal degenerative diseases, treatment approaches are limited to regenerative strategies, visual prostheses, or standard vision rehabilitation. ${ }^{4,7,8}$ Human retinal transplantation has followed many years of experimental research showing that transplanted RPE cells have the potential to rescue photoreceptors. ${ }^{3,4,9}$ Therefore, healthy stem cell derived RPE-like cells, delivered as an integer epithelial sheet on a BM prosthetic substrate, represents a promising therapeutic approach in AMD., ${ }^{2,3,10,11}$ A BM prosthetic substrate should be able to perform the BM's primary functions, that is, regulate the (bio-) molecules passive diffusion between choroid and RPE; provide physical support for RPE adhesion, migration, and perhaps differentiation; and act as a division barrier for cell migration. ${ }^{6}$ In addition, these substrates should be biocompatible, able to maintain the RPE phenotype, and exhibit favorable surgical properties (handling stability and resistance to tear). ${ }^{3,10}$ Several biocompatible substrates to patch or replace diseased BM for the delivery and long-term survival of RPE transplants have been reported, namely polyethylene terephthalate and poly(L-lactide-co- $\varepsilon$-caprolactone) films and electrospun substrates; ${ }^{10}$ montmorillonite clay-based polyurethane substrates; ${ }^{12}$ methacrylate-based copolymer electrospun fibrous scaffold; ${ }^{13}$ ultrathin and biofunctionalized polyimide membranes; ${ }^{7}$ and ultrathin collagen membranes. ${ }^{14}$

Gluconacetobacter xylinus bacteria synthesize bacterial cellulose $(\mathrm{BC})$ in a complex process that results in a three-

Received: January 29, 2015

Revised: $\quad$ March 5, 2015

Published: March 6, 2015 

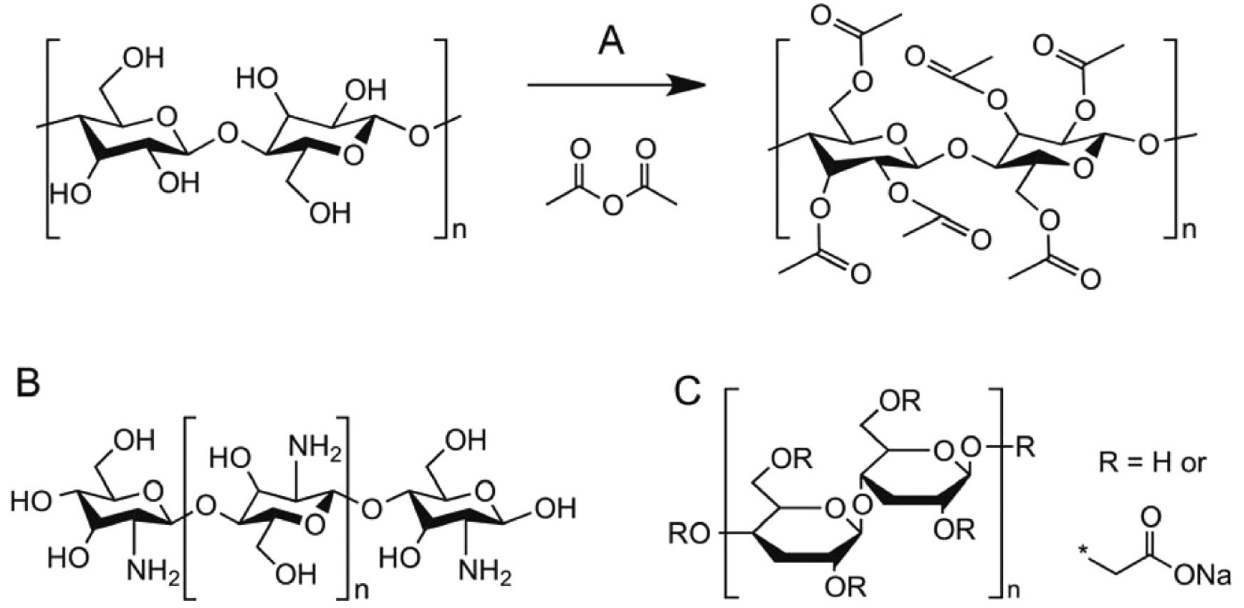

Figure 1. Scheme of bacterial cellulose (BC) acetylation reaction (A), and molecular structures of chitosan (B) and carboxymethyl cellulose (C).

dimensional gelatinous nanofibrillar structure formed on the surface of a liquid medium. The biosynthetic process involves the polymerization of single glucose residues into linear $\beta$-1,4glucan chains, the extracellular secretion of these linear chains, and the assembly and crystallization of the glucan chains into hierarchically composed ribbons. ${ }^{15,16}$ The combination of BC's unique structural and mechanical properties, with biocompatibility, moldability in situ, permeability for gas and fluid exchange, high hydrophilicity, transparency, and nontoxicity, make it an attractive candidate for biomedical applications. ${ }^{16-22}$ Its exceptional properties have sustained the elevator pitch of several BC applications, especially in the biomedical field, where temporary skin substitutes and artificial blood vessels appear as patented products (Biofill and BASYC). The potential use of $\mathrm{BC}$ as a biomaterial includes artificial skin, ${ }^{17}$ vascular grafts, ${ }^{20,23,24}$ conduits in urinary reconstruction and diversion, ${ }^{25}$ cartilage replacement, ${ }^{26}$ bone regeneration, ${ }^{27}$ artificial cornea, ${ }^{28}$ tissue engineering hydrogels, ${ }^{29}$ and scaffolds. ${ }^{30}$ Also, $\mathrm{BC}$ is not biodegradable in the human body, which can be beneficial for its possible use in AMD treatment, since the use of substrates that are degradable are difficult to handle and may induce retinal degeneration due to material degradation. ${ }^{30-36}$

In this work, we evaluated the ability of RPE cells to adhere and grow on BC-based substrates, with the ultimate goal of assessing the $\mathrm{BC}$ potential as a novel substrate for $\mathrm{RPE}$ transplantation in retinal degenerative diseases. Since surface properties play an important role in cell adhesion and proliferation, BC's surface was modified to improve the cellmaterial interactions. Two approaches were used, namely, acetylation and polysaccharide adsorption using either chitosan or carboxymethyl cellulose. The first modification decreases BC's surface hydrophilicity, while the second increases protein adsorption by the incorporation of amine or carboxymethyl groups onto the surface of $\mathrm{BC}$ nanofibers. ${ }^{37,38} \mathrm{BC}$ substrates were characterized according to their surface chemistry, topography, free energy, wettability, permeability, dimensional stability (handling stability and swelling), mechanical properties and amount of endotoxins. RPE cultures were performed to evaluate cell viability and proliferation on the BC substrates.

\section{MATERIAL AND METHODS}

Bacterial Cellulose Production. Bacterial cellulose (BC) substrates were produced by static culture of G. xylinus (ATCC
53582), as reported elsewhere. ${ }^{20,21}$ Cultures were performed in $1 \mathrm{~L}$ Erlenmeyer flasks with $200 \mathrm{~mL}$ of Hestrin-Schramm culture medium for 1 month. The resulting BC sheet was washed with abundant tap water and placed for $24 \mathrm{~h}$ in a $1.0 \mathrm{~N} \mathrm{NaOH}$ solution, at room temperature, to remove residual medium and bacteria. The alkaline residues were removed through several washing steps with distilled water. Afterward, the BC sheets were sliced into thin pellicles (with 2 $\mathrm{mm}$ thickness on average), cut into the desired geometric forms, dried in an oven at $50{ }^{\circ} \mathrm{C}$ for $8 \mathrm{~h}$. Control samples (unmodified $\mathrm{BC}$ ) were further autoclaved $\left(121^{\circ} \mathrm{C}, 20 \mathrm{~min}\right)$ and maintained in sterile distilled water. Only dried $\mathrm{BC}$ was used to reduce its water-holding capacity and, consequently, minimize undesired swelling. ${ }^{15}$ Thickness measurements of the dried BC samples were performed using a digital micrometer (No. 293-5, Mitutoyo, Japan) in each sample to normalize the swelling estimation data and for the stress-strain assays. The average thickness used for all experiments was $41.6 \pm 2.2$ $\mu \mathrm{m}$.

Surface Modification. Dried BC samples were surface modified by two different approaches: (1) acetylation (Figure 1A) to introduce acetate functional groups; and (2) polysaccharide adsorption using either chitosan (Figure 1B) or carboxymethyl cellulose (CMC; Figure 1C) to introduce amine and carboxymethyl groups, respectively. The surface area per reaction volume ratio was approximately $1 \mathrm{~mL} \cdot \mathrm{cm}^{-2}$ of BC samples, for both modification approaches.

For the surface acetylation process, dehydrated samples were first added to the reaction mixture consisting of $40 \mathrm{~mL}$ acetic acid (Fisher), $50 \mathrm{~mL}$ toluene (Fisher) and $0.2 \mathrm{~mL}$ perchloric acid (Panreac). Afterward, $8 \mathrm{~mL}$ of anhydride acetic (Merck) was added, and the reaction mixture was stirred for $15 \mathrm{~min}$ at room temperature. ${ }^{38}$ Afterward, acetylated $\mathrm{BC}$ substrates $(\mathrm{ABC})$ were washed, sterilized in ethanol, and maintained in sterile distilled water until use.

Chitosan (85\% deacetylated, Sigma) and CMC (MW: $2.5 \mathrm{kDa}$; DS: 0.45-0.55, British Drug Houses) were adsorbed onto BC substrates, as described in the literature. ${ }^{38}$ These polysaccharides were each first dissolved at $1 \mathrm{mg} \cdot \mathrm{mL}^{-1}$ in an aqueous acidic solution of $50 \mathrm{mM}$ sodium acetate buffer (SAB) containing $50 \mathrm{mM} \mathrm{NaCl}(\mathrm{pH} \mathrm{5.0)}$. BC samples were added to either $\mathrm{CMC}$ or chitosan solutions and allowed to adsorb for $18 \mathrm{~h}$ at room temperature, under constant stirring. $\mathrm{BC}$ samples with adsorbed chitosan (CBC) and $\mathrm{CMC}(\mathrm{CMBC})$ were then washed three times with $\mathrm{SAB}$ solution (1 h each time, under constant stirring, at room temperature) to remove nonadsorbed polysaccharides, autoclaved in $\mathrm{SAB}$ solution and maintained in sterile $\mathrm{PBS}$ solution.

Surface Chemistry. Attenuated total reflectance-Fourier transform infrared (ATR-FTIR) spectroscopy was used to identify surface functional groups, using a PerkinElmer Spotlight 300 FTIR microscope with Spectrum 100 FTIR spectrometer. All spectra correspond to the average of 100 scans measured at a resolution of $4 \mathrm{~cm}^{-1}$. The 
vibration transition frequencies of each spectrum were baseline corrected, and the absorbance was normalized between 0 and 1 .

Surface Energy and Wettability. Static contact angle measurements were performed using the sessile drop method to assess the degree of surface hydrophobicity and surface free energy (SFE, $\gamma$ ). However, this method requires a flat and smooth solid surface. Since the surface of BC substrates may present some roughness, measured contact angles are "apparent" contact angles, as previously described for rough surfaces. ${ }^{39}$ Therefore, the apparent contact angles were used to evaluate surface wettability and estimate the surface free energy. Static contact angles were measured at room temperature, using a Dataphysics OCA-20 drop shape analysis system (DataPhysics Instruments $\mathrm{GmbH}$, Filderstadt, Germany) controlled by SCA20 software (droplet size $3 \mu \mathrm{L}$ ). The water contact angle directly indicates the degree of hydrophobicity. For SFE estimation, the van OssChaudhury-Good (vOCG) method was selected, as it provides information regarding the interfacial acid-base interactions. ${ }^{40,41}$ Through this method, the forces involved in a solid SFE can be divided into two components: Lifshitz van der Waals or dispersive $\left(\gamma^{\mathrm{LW}}\right)$ and acid-base or polar $\left(\gamma^{\mathrm{AB}}=\left(\gamma^{+} \gamma^{-}\right)^{2}\right)^{1 / 2}$, where the latter can be further subdivided in basic $\left(\gamma^{-}\right)$and acidic $\left(\gamma^{+}\right)$constituents. ${ }^{40,41}$ The equation that describes the interaction of these forces is the following:

$$
\gamma_{\mathrm{L}}(1+\cos \theta)=2 \sqrt{\gamma_{\mathrm{S}}^{\mathrm{LW}} \gamma_{\mathrm{L}}^{\mathrm{LW}}}+2 \sqrt{\gamma_{\mathrm{S}}^{+} \gamma_{\mathrm{L}}^{-}}+2 \sqrt{\gamma_{\mathrm{S}}^{-} \gamma_{\mathrm{L}}^{+}}
$$

Since there are three unknowns, $\gamma_{S}^{\mathrm{LW}}, \gamma_{S}^{+}$and $\gamma_{S}^{-}$, the solution of a system of three independent linear equations is needed to determine these quantities. Therefore, three reference liquids, with known energy components (see Table S1), were used, one nonpolar (bromonaphthalene) and two bipolar liquids (water and formamide). ${ }^{41-43}$

Permeation. To assess substrate permeation, diffusion experiments were performed based in previous works. ${ }^{7,44}$ The three systems used were composed of two chambers, each with a capacity of $1.2 \mathrm{~mL}$, connected with a circular opening with $10 \mathrm{~mm}$ diameter. Since the diffusion setup was equivalent to the one performed by Julien et al., the same model (eq 2) was used to estimate the permeation coefficient $(P)$ :

$$
P \cdot t=-\log \left[\left(C_{0}-2 C\right) / C_{0}\right] 2303(L V / 2 S)
$$

where $C$ is the concentration $\left(\mathrm{g} \cdot \mathrm{cm}^{-3}\right)$ in the acceptor chamber at a given time point $t(\mathrm{~s}) ; C_{0}$ is the concentration in the donor chamber at $t=0 ; P$ is the permeability constant $\left(\mathrm{cm}^{2} \cdot \mathrm{s}^{-1}\right) ; L$ is the membrane thickness $(\mathrm{cm}) ; V$ is the volume of the solutions in the chambers $\left(\mathrm{cm}^{3}\right)$; and $S$ is the membrane surface area $\left(\mathrm{cm}^{2}\right)$. The permeability constant can be obtained from the slope when plotting the right side of the equation as a function of time $(t)$. The donor chamber was filled with a $4 \% \mathrm{w} / \mathrm{v}$ solution of polyethylene glycol (PEG), and the acceptor chamber was filled with distilled water. Two PEGs with different molecular weights were used, $35 \mathrm{kDa}$ (Sigma) and $300 \mathrm{kDa}$ (Acros). The $\mathrm{BC}$ substrates were placed between the two chambers, and PEG diffused passively across the substrate from the donor chamber to the acceptor chamber. Samples were taken from the acceptor chamber at several time points and the concentration was determined by refraction index detection (six replicates per time point). Additionally, samples of cellulose acetate $(0.45 \mu \mathrm{m}$ pore size, Whatman) were used as a reference permeable substrate, under the same experimental conditions.

Dimensional Stability. The in vitro stability of BC substrates was evaluated by incubating samples in phosphate buffered saline (PBS) solution (137 mM NaCl, $2.7 \mathrm{mM} \mathrm{KCl}, 8 \mathrm{mM} \mathrm{Na} \mathrm{HPO}_{4}, 2 \mathrm{mM}$ $\mathrm{KH}_{2} \mathrm{PO}_{4}, \mathrm{pH}$ 7.4) at room temperature for 12 weeks and analyzing them for handling stability by manipulating the membranes with tweezers. To assess the occurrence of substrate swelling, these same samples were weighted at different time points (1, 4, and 12 weeks). Twelve specimens were measured for each substrate. Since the samples presented variable thicknesses, swelling data taken individually was normalized by their respective initial volume using the following equation:

$$
\text { swelling/volume }=\frac{\text { mass }_{\text {wet }}^{t}-\text { mass }_{\mathrm{dry}}}{\text { mass }_{\mathrm{dry}} \times \text { volume }}
$$

where mass $\mathrm{dry}_{\mathrm{d}}$ was the initial mass in the dry state, and mass ${ }_{\text {wet }}^{t}$ was the mass measured in wet state at each time point, $t$.

Mechanical Properties. Stress-strain assays were performed to evaluate the mechanical properties of the developed substrates, using a Shimadzu Universal Testing Machine (AG-IS with a $50 \mathrm{~N}$ load cell) in tensile mode, at a strain rate of $0.5 \mathrm{~mm} \cdot \mathrm{min}^{-1}$ and at room temperature. The samples were immersed for approximately $5 \mathrm{~min}$ in distilled water, immediately prior to the tensile tests. From the stressstrain data, the modulus of elasticity $(E)$ was calculated in the linear zone of elasticity, between 0 and $1 \%$ of strain, for all the samples. The maximum stress $\left(\sigma_{\max }\right)$ and the strain-to-failure $\left(\varepsilon_{\text {break }}\right)$ were also determined. Measurements were performed on five specimens of each type and the mean values and standard deviation were calculated.

Endotoxin Analysis. BC substrates were analyzed for the presence of endotoxin using the limulus amebocyte lysate test (Pierce LAL Chromogenic Endotoxin Quantitation kit, Thermo Scientific). Substrate $(\mathrm{BC}, \mathrm{ABC}, \mathrm{CBC}$ and $\mathrm{CMBC})$ samples were autoclaved in distilled water. Each substrate (approximately $0.88 \mathrm{~mm}^{3}$ of volume) was immersed in $40 \mathrm{~mL}$ of pyrogen-free water. The assay was performed according to the kit supplier instructions. The reaction was stopped with $25 \%$ acetic acid and the absorbance was measured at 405 nm.

Retinal Pigment Epithelium Culture. Human RPE cells (hTERT-RPE1, ATCC CRL-4000), immortalized by the transfection with human telomerase gene (hTERT), were previously described as having a normal RPE phenotype. ${ }^{45}$ In this work, these cells were used between 200 and 250 population doublings and were grown in Dulbecco's MEM/Ham's F12 (1:1 mixture) culture media supplemented with $10 \% \mathrm{v} / \mathrm{v}$ fetal bovine serum (FBS), $100 \mathrm{U} \cdot \mathrm{mL}^{-1}$ penicillin, and $100 \mu \mathrm{g} \cdot \mathrm{mL}^{-1}$ streptomycin (DMEM/F12 complete medium) at $37^{\circ} \mathrm{C}$ in a humidified atmosphere of $95 \%$ air and $5 \% \mathrm{CO}_{2}$. All cell culture reagents were purchased from Biochrom, unless stated otherwise. At confluence, hTERT-RPE cells were harvested with $0.05 \%(\mathrm{w} / \mathrm{v})$ trypsin-EDTA and then subcultured in the same medium. PBS was used for all washing steps. The exposure media (EM) used for the viability assays consisted of DMEM (without phenol red) supplemented with $100 \mathrm{U} \cdot \mathrm{mL}^{-1}$ penicillin and $100 \mu \mathrm{g}$. $\mathrm{mL}^{-1}$ streptomycin. Cells were seeded on the substrates and on tissue culture polystyrene (TCP; used as a control surface) at a density of 40000 cells $\cdot \mathrm{cm}^{-2}$.

Cell Viability and Proliferation Studies. Viability studies were performed at three time points (3, 7, and 14 days) to assess cell proliferation. Three independent cultures per condition were performed. Cell viability was evaluated using the 3-(4,5-dimethylthiazol-2-yl)-5-(3-carboxymethoxyphenyl)-2-(4-sulfophenyl)-2H-tetrazolium (MTS) assay (Promega) and the LIVE/DEAD Viability/ Cytotoxicity kit for mammalian cells (Invitrogen). The MTS assay measures the metabolic activity of viable cells via its dehydrogenase activity. Cells were washed, incubated for $2 \mathrm{~h}$ with $20 \mu \mathrm{L}$ MTS solution reagent in $100 \mu \mathrm{L} \mathrm{EM}$, and then the absorbance was recorded at $490 \mathrm{~nm}$ with a 96-well plate reader. The LIVE/DEAD kit provides a two-color fluorescence cell viability assay, based on the simultaneous determination of live (green) and dead (red) cells with two probes, Calcein AM and Ethidium Homodimer (EthD-1), that measure intracellular esterase activity and plasma membrane integrity, respectively. Cell cultures were incubated for $30 \mathrm{~min}$ in $200 \mu \mathrm{L}$ EM with $20 \mu \mathrm{L}$ LIVE/DEAD working solution $(2 \mu \mathrm{M}$ EthD-1 and $4 \mu \mathrm{M}$ Calcein AM in PBS pH 7.4). Afterward, the substrates were observed in a fluorescence microscope (Leica DMIRE2, with a DFC350FX camera) and pictures were taken from six random fields for each substrate condition.

Scanning Electron Microscopy. For surface topography analysis, the substrates were dried, sputter coated with gold, and transferred to the microscopic carrier. Samples from 14 days in vitro culture assays were fixed with $2.5 \%$ glutaraldehyde in PBS solution for $1 \mathrm{~h}$, at room temperature, washed with distilled water, dehydrated through six 

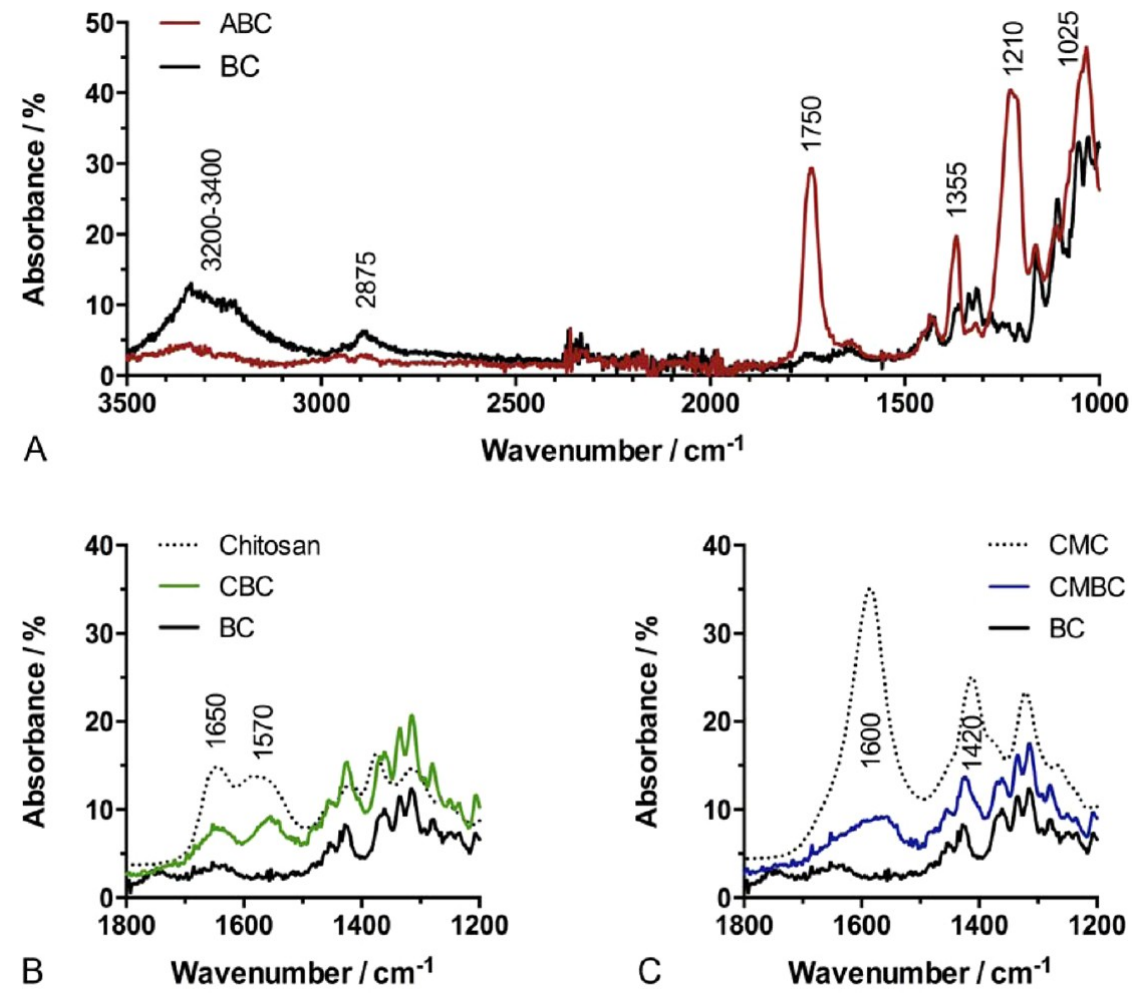

Figure 2. ATR-FTIR spectra of substrates in the following conditions: (A) unmodified bacterial cellulose (BC) and acetylated BC (ABC); (B) unmodified $\mathrm{BC}$, chitosan adsorbed $\mathrm{BC}(\mathrm{CBC})$, and chitosan; $(\mathrm{C})$ unmodified $\mathrm{BC}$, carboxymethyl cellulose (CMC), and $\mathrm{CMC}$ adsorbed $\mathrm{BC}$ (CMBC).

changes of ethanol (55, 70, 80, 90, 95, and 100\%, 30 min each), and finally sputtered with gold. Images were obtained using a Leica Cambridge S360 scanning electron microscope (SEM) with electron beam energy of $15 \mathrm{kV}$.

Statistics. All data are presented as the mean \pm standard error mean. Six independent replicas were analyzed for each condition, unless stated otherwise. Statistical analysis of variance (ANOVA) and the Tukey multiple comparison test were used to compare results within and between each time point for each substrate condition. Significant statistical differences were assigned to the groups with a $p$ value less than 0.05 .

\section{RESULTS AND DISCUSSION}

Substrate Characterization. Cell adhesion to substrates is affected by surface properties such as wettability, topography, surface charge, and chemical functionalities. ${ }^{46,47}$ ATR-FTIR spectroscopy was used to confirm BC's surface modification via acetylation and polysaccharide adsorption using chitosan and CMC (Figure 2). After surface acetylation (Figure 2A), BC substrates show a decrease in the alcohol $\mathrm{O}-\mathrm{H}$ stretch $(3200-$ $\left.3400 \mathrm{~cm}^{-1}\right)$ and in the alkane $\mathrm{C}-\mathrm{H}$ stretch peaks $\left(2875 \mathrm{~cm}^{-1}\right)$. On the other hand, there is a significant increase in the ester $\mathrm{C}=\mathrm{O}$ stretch $\left(1750 \mathrm{~cm}^{-1}\right)$, in the alkane $-\mathrm{C}-\mathrm{H}$ bending $\left(1355 \mathrm{~cm}^{-1}\right)$, and in the two peaks relative to the ester $\mathrm{C}-\mathrm{O}$ stretch $\left(1210,1025 \mathrm{~cm}^{-1}\right)$. This suggests the successful functionalization of $\mathrm{BC}$ 's surface $-\mathrm{OH}$ groups by their conversion into acetate groups. Also, adsorption of chitosan onto the surface of $\mathrm{BC}$ nanofibers could be evidenced by an increase in the chitosan characteristic bands in BC-modified samples (Figure $2 \mathrm{~B})$ : amide I $\left(1650 \mathrm{~cm}^{-1}\right)$ and amide II (1570 $\mathrm{cm}^{-1}$ ). This is in accordance with previous works on chitosancellulose substrates. ${ }^{38,48} \mathrm{CMC}$ original spectrum indicates a significant peak at $1590 \mathrm{~cm}^{-1}$ that corresponds to carboxylic acid $\mathrm{C}=\mathrm{O}$ stretch. This peak can also be observed, although in a much lower intensity, in CMBC substrates (Figure 2C). Additionally, CMC shows other peaks that were almost undetectable on the $\mathrm{CMBC}$ substrates, namely, the carboxylic acid $\mathrm{O}-\mathrm{H}$ bend $\left(1415 \mathrm{~cm}^{-1}\right)$ and the carboxylic acid $\mathrm{C}-\mathrm{O}$ stretch $\left(1320 \mathrm{~cm}^{-1}\right)$. Although the carboxylic acid peak is weak, its presence indicates the incorporation of the carboxymethyl groups in the $\mathrm{BC}$ surface.

Therefore, surfaces with different functional groups were obtained after modification (hydroxyl for unmodified $\mathrm{BC}$, ester for $\mathrm{ABC}$, amine for $\mathrm{CBC}$, and carboxymethyl groups for $\mathrm{CMBC}){ }^{37,48-51}$ In this work, aiming at the development of substrates with distinct surface properties, excess solutions of $\mathrm{CMC}$ and chitosan were used to saturate the nanofibers with either polymer. Regarding CMC, the protocol used has been described to lead to irreversible CMC adsorption to cellulose. Although the FTIR data suggest the presence of CMC functional groups at the $\mathrm{BC}$ surface, the amount of $\mathrm{CMC}$ being incorporated could not be assessed. Also, given the small mass of the $\mathrm{BC}$ substrates, mass gain from polymer adsorption could not be detected within the weighing sensibility available. Future research will involve tailoring the amount of adsorbed polymers onto the $\mathrm{BC}$ surface and the NMR characterization of the modified substrates. The incorporation of different surface chemical functionalities may affect surface wettability, charge, roughness and porosity, and in turn lead to different cell responses. Surface wettability influences protein and cellular adhesion, where highly hydrophilic materials do not allow stable adsorption of cell adhesion-mediating proteins or they are bound very weakly. ${ }^{52,53}$ Anionic-hydrophilic surfaces bearing relatively weak base functional groups resist protein adsorption by hydrogen-bonding to water so strongly that 

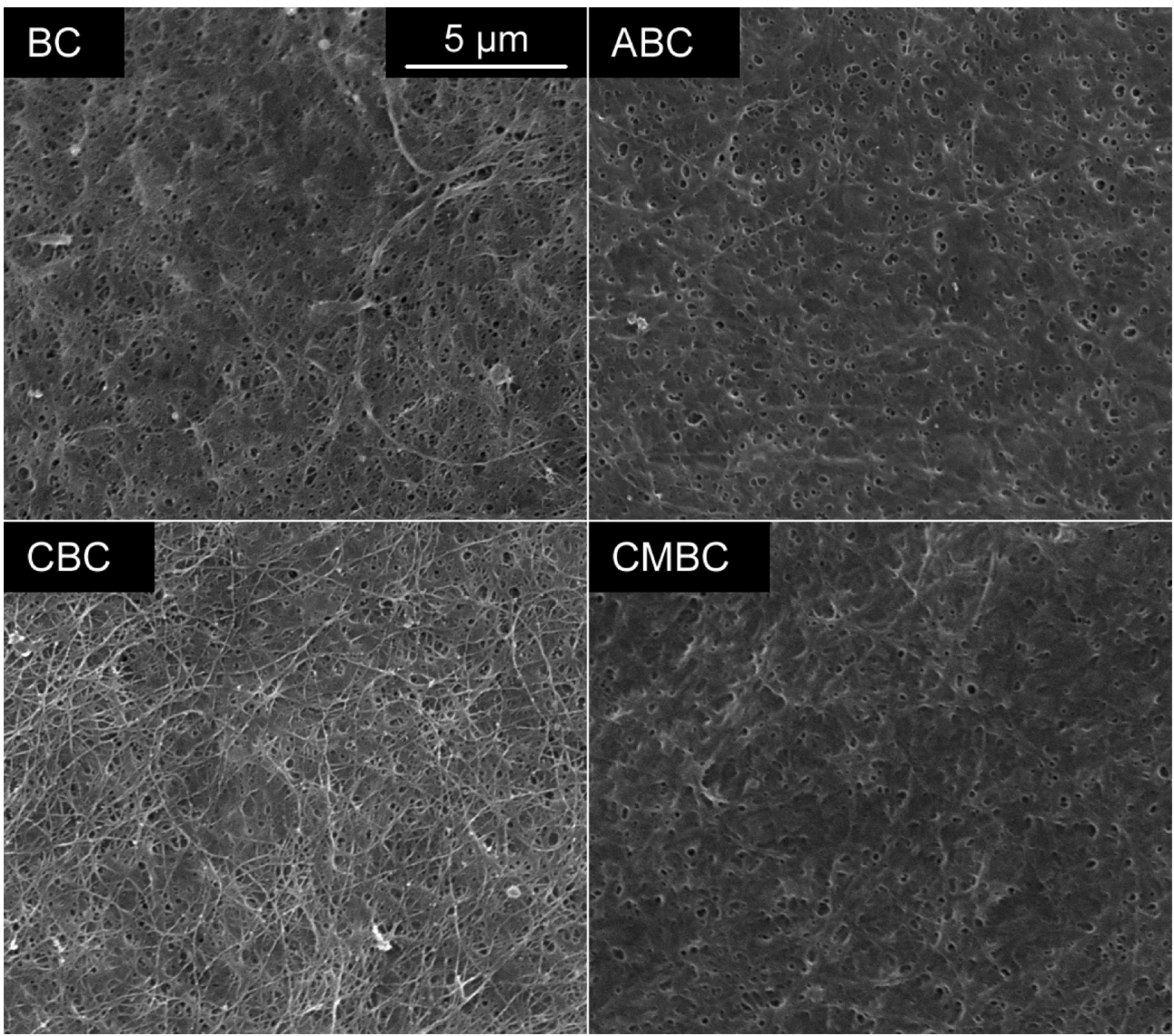

Figure 3. Scanning electron micrographs of the surface topography for the different bacterial cellulose substrates: bacterial cellulose (BC), acetylated $\mathrm{BC}(\mathrm{ABC})$, chitosan adsorbed $\mathrm{BC}(\mathrm{CBC})$, and carboxymethyl cellulose adsorbed $\mathrm{BC}(\mathrm{CMBC})$.

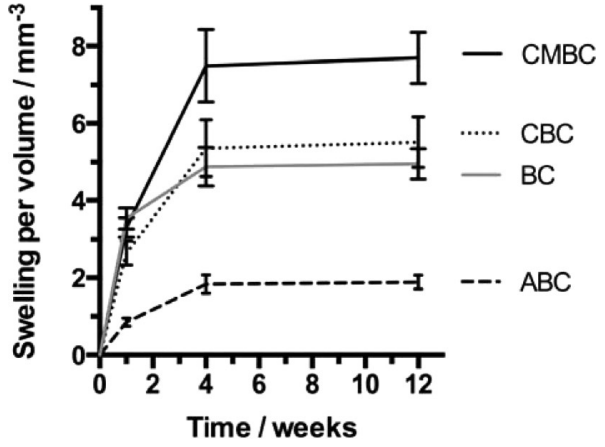

Figure 4. Water swelling of unmodified bacterial cellulose (BC), acetylated $\mathrm{BC}(\mathrm{ABC})$, chitosan adsorbed $\mathrm{BC}(\mathrm{CBC})$, and carboxymethyl cellulose adsorbed $\mathrm{BC}(\mathrm{CMBC})$ substrates in $\mathrm{PBS} \mathrm{pH}$ 7.4. A total of 12 replicas were performed per condition. All swelling profiles are statistically different for the exception of $\mathrm{BC}$ and $\mathrm{CBC}$.

protein cannot displace the interphase water and enter the adsorbed state..$^{53-55}$ On the other hand, optimal cell adhesion and the adsorption of cell adhesion-mediating molecules or proteins are promoted in moderately hydrophilic substrates, which show water contact angles in the range of $40-70^{\circ} .47,53$ Since the substrates may present some roughness, the Young equilibrium or ideal contact angles, which include the roughness factor, could not be determined. Instead, the apparent contact angles were used to assess the surface hydrophobicity and free energy. ${ }^{39}$ The measured apparent contact angles, as well as the free energy and charge information, are presented in Table S2.

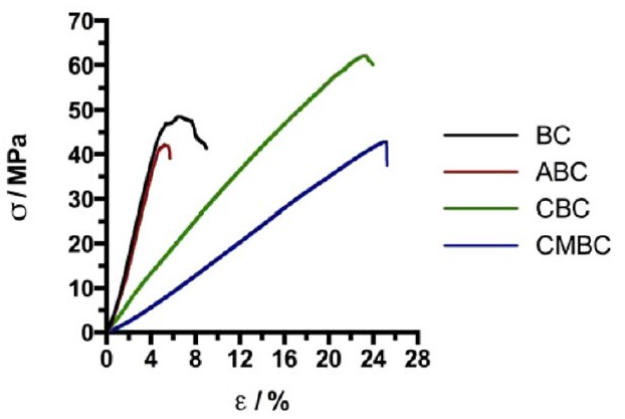

Figure 5. Stress-strain measurements obtained for unmodified bacterial cellulose $(\mathrm{BC})$, acetylated $\mathrm{BC}(\mathrm{ABC})$, chitosan adsorbed $\mathrm{BC}(\mathrm{CBC})$, and carboxymethyl cellulose adsorbed $\mathrm{BC}(\mathrm{CMBC})$. Five replicas were used.

Surface acetylation increases water contact angle values from $23^{\circ}$ to approximately $65^{\circ}$, while polysaccharide adsorption did not change the high hydrophilic degree of BC. Similarly to water, the formamide and bromonaphthalene contact angles did not change significantly after chitosan and CMC adsorption. Therefore, the calculated surface free energy components differed only for the $\mathrm{ABC}$ substrates: the $\gamma^{\mathrm{LW}}$ energy component increased from $37.5(\mathrm{BC})$ to $42.6 \mathrm{mN} \cdot \mathrm{m}^{-1}$ $(\mathrm{ABC})$; conversely, the value of the $\gamma^{\mathrm{AB}}$ energy component strongly decreased following acetylation from $15(\mathrm{BC})$ to 4 $\mathrm{mN} \cdot \mathrm{m}^{-1}$ (ABC).

The change in the basic energy component, $\gamma^{-}$, was the most substantial, from $50.7 \mathrm{mN} \cdot \mathrm{m}^{-1}$ (BC) to $13.4 \mathrm{mN} \cdot \mathrm{m}^{-1}(\mathrm{ABC})$. 


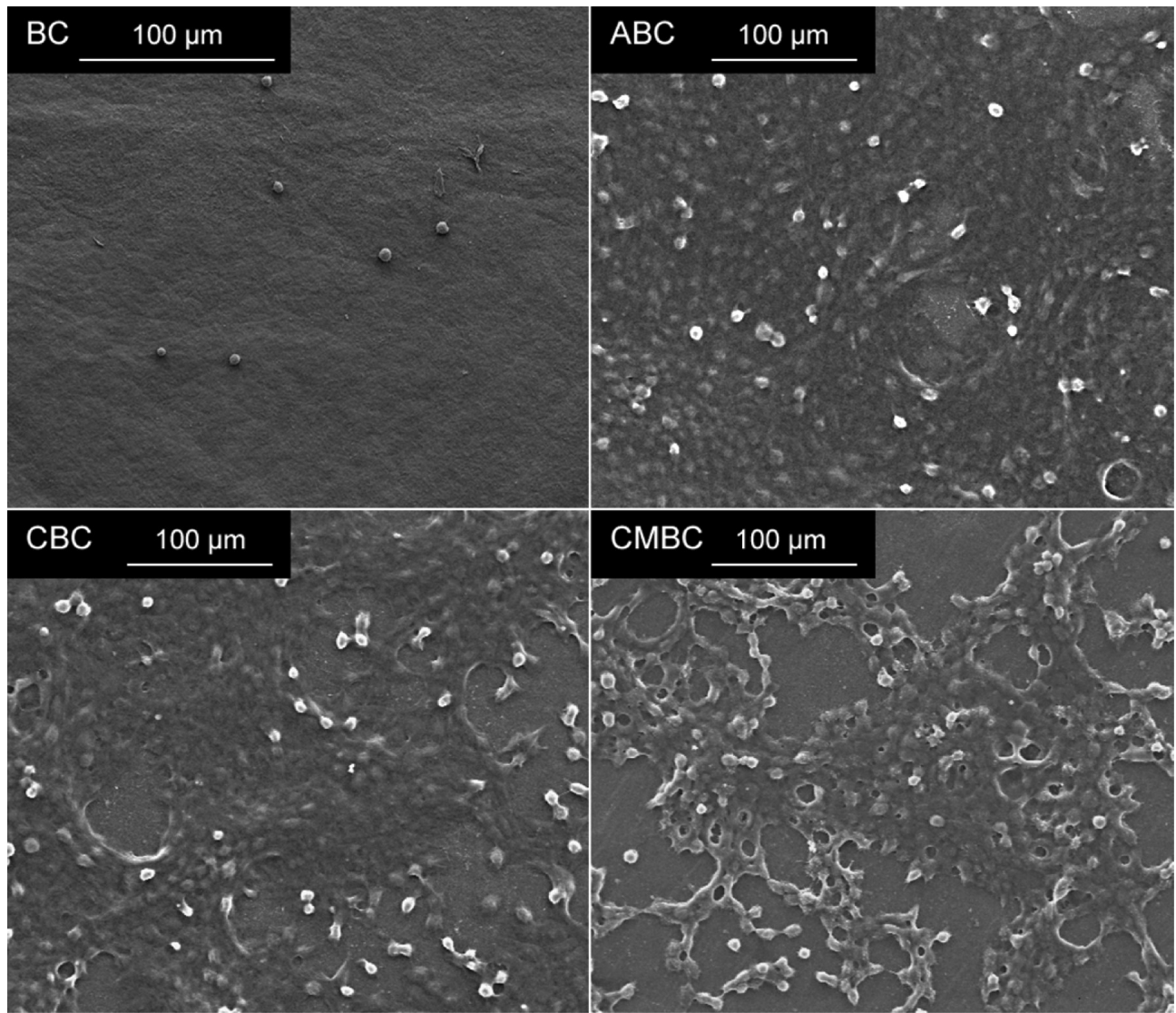

Figure 6. Scanning electron micrographs of hTERT-RPE1 cells grown on unmodified bacterial cellulose (BC), acetylated BC (ABC), chitosan adsorbed $\mathrm{BC}(\mathrm{CBC})$, and carboxymethyl cellulose adsorbed $\mathrm{BC}(\mathrm{CMBC})$ substrates after 14 days of cell culture.

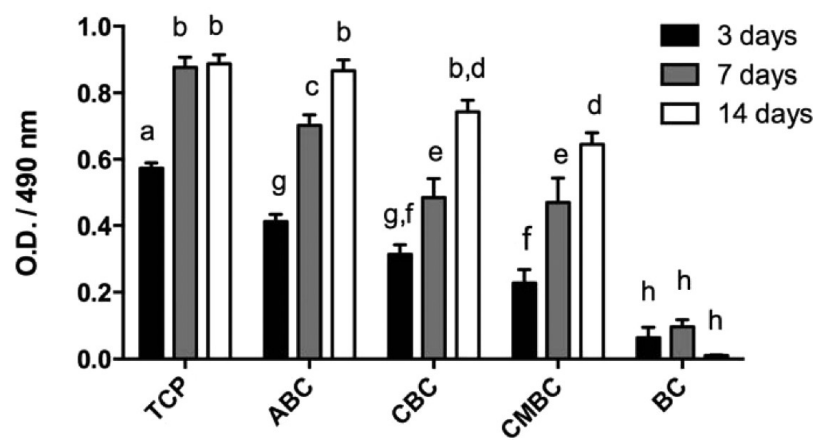

Figure 7. Metabolic activity after 3, 7, and 14 days of HTERT-RPE cells cultured in bacterial cellulose $(\mathrm{BC})$, acetylated $\mathrm{BC}(\mathrm{ABC})$, chitosan $\mathrm{BC}(\mathrm{CBC})$, and carboxymethyl cellulose adsorbed $\mathrm{BC}$ $(\mathrm{CMBC})$ substrates, as well as in tissue culture polystyrene (TCP, control surface). Optical density (O.D.) was measured in three independent MTS assays (12 replicas for each substrate condition in each assay). The same letters are given to data not different statistically.

BC substrates had only a residual positive charge $\left(\gamma^{+}\right.$, Table S2), with acid-base forces resulting from negative charges. The decrease in the polar forces after acetylation is coherent with the decreased surface hydrophilicity observed in the $A B C$ substrates. Also, amine, hydroxyl, and carboxyl functional groups confer relatively weak acid-base strength to the surface, in contrast with ion-exchange functionalities, such as carboxymethyl groups that confer a strong acid-base strength. ${ }^{54}$ However, CMBC substrates did not show an increased acid-base energy. Also, a very weak carboxylic acid peak was observed in ATR-FTIR spectra (Figure 2C), which may indicate a low incorporation of carboxymethyl groups following CMC adsorption. In a cell adhesion study with fibroblasts cultured on glass and silicon substrata, the presence of amine and carboxyl groups led to a strong cell interaction with the surfaces when compared to those with hydroxyl groups, which was associated with an enhanced activity of integrins. ${ }^{56}$ Therefore, modified BC substrates were expected to induce stronger interaction with cells than the unmodified $\mathrm{BC}$ ones, specially the $\mathrm{ABC}$ ones due to its moderate hydrophilicity.

In addition to good surface interaction with biological entities, these substrates must not constitute an obstacle to the diffusion of nutrients and byproducts. The permeation coefficients obtained in the control samples were $4.2 \times 10^{-6}$ and $3.8 \times 10^{-6} \mathrm{~cm}^{2} \cdot \mathrm{s}^{-1}$, for PEG $35 \mathrm{kDa}$ and PEG $300 \mathrm{kDa}$, respectively. All surface-modified $\mathrm{BC}$ substrates presented similar permeation coefficients that were, on average, $2.9 \pm$ $0.2 \times 10^{-6}$ and $1.8 \pm 0.2 \times 10^{-6} \mathrm{~cm}^{2} \cdot \mathrm{s}^{-1}$, for PEG 35 and PEG $300 \mathrm{kDa}$, respectively. Although these values were slightly lower than the ones for the control, BC substrates were found to be well suited for RPE transplantation, as they allow fluid transport and are permeable to macromolecules up to a molecular weight of $300 \mathrm{kDa}$, which is the maximum that is transported by RPE cells. ${ }^{6}$

Since permeation coefficients did not differ between BC conditions, it was expected the presence of similar porous structures in all $\mathrm{BC}$ substrates, which was confirmed through the SEM analysis of $\mathrm{BC}, \mathrm{ABC}, \mathrm{CBC}$, and $\mathrm{CMBC}$ substrates (Figure 3). It is important to notice that while dehydration 


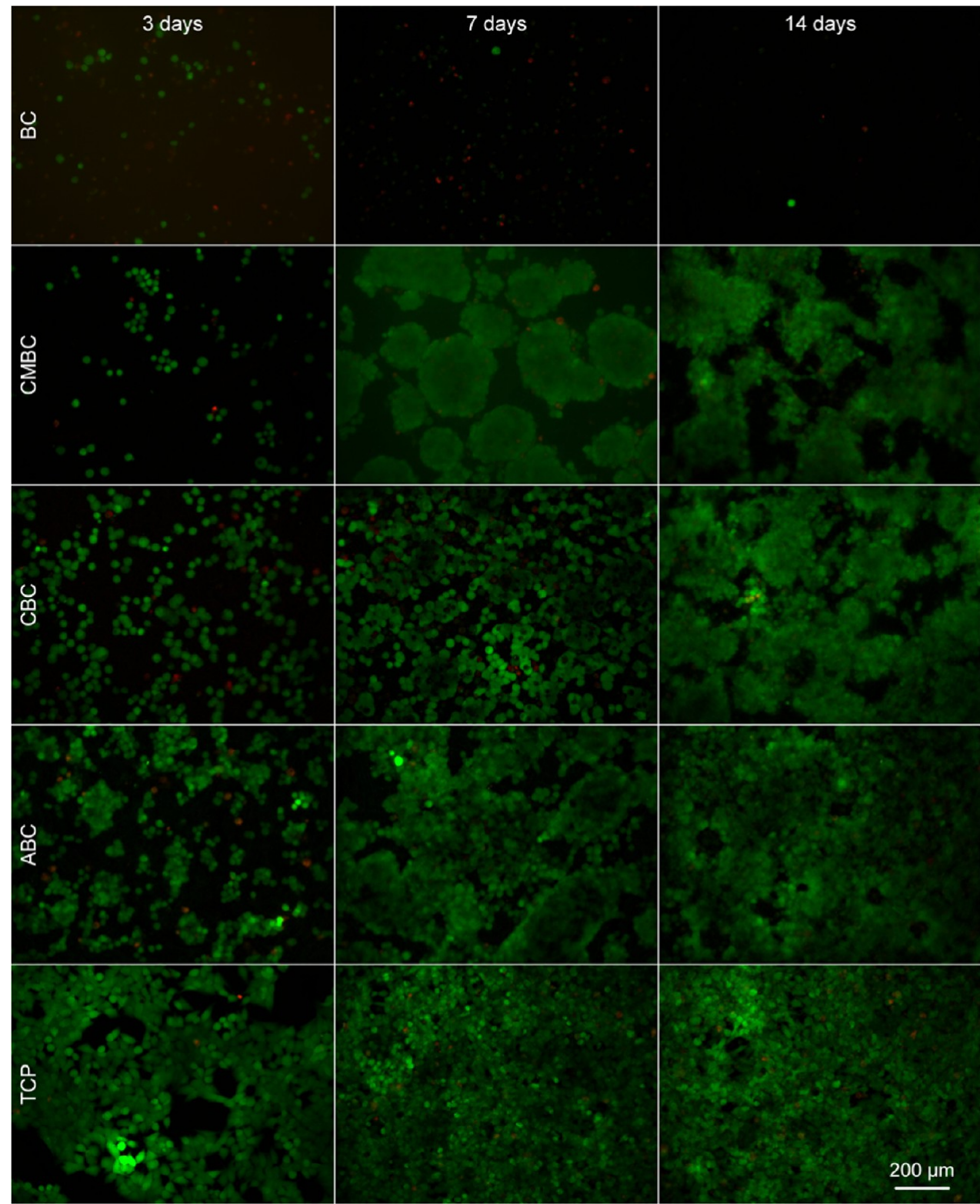

Figure 8. Representative LIVE/DEAD fluorescence micrographs of HTERT-RPE1 cells cultured for 3, 7, and 14 days on unmodified bacterial cellulose $(\mathrm{BC})$, acetylated $\mathrm{BC}(\mathrm{ABC})$, chitosan adsorbed $\mathrm{BC}(\mathrm{CBC})$, carboxymethyl cellulose adsorbed $\mathrm{BC}(\mathrm{CMBC})$, and tissue culture polystyrene (TCP, control surface).

strongly reduces the $\mathrm{BC}$ porosity, it is still a porous and permeable material (as observed from the current permeability assays for polymers of up to $300 \mathrm{kDa}$ ). Therefore, it can be expected that, for example, CMC (which has a MW of $2.5 \mathrm{kDa}$ ) penetrates through the pores of $\mathrm{BC}$. This adsorption may not impact the mechanical properties as herein shown. The BC porosity is an advantageous feature comparing to other materials that have been proposed for the envisaged application, namely, polydimethylsiloxane, ${ }^{57}$ polypropylene, ${ }^{58}$ and parylene that was already patented for RPE transplantation (Patent Publication No.: US20120009159 A1; publication date: 12 Jan 2012). All the referred materials are nonporous. Besides, a nonbiodegradable substrate has to meet the passive diffusion requirements to be a BM substitute, which was herein demonstrated for all BC substrates, contrarily to those materials. From the above, parylene $\mathrm{C}$ has been described to be semipermeable to macromolecules up to $250 \mathrm{kDa}$, but only if the thickness of the material does not surpass $0.3 \mu \mathrm{m} .{ }^{59}$ However, this level of ultrathin thickness may be too difficult to manipulate with surgical instruments during a transplantation procedure.

Slight differences in surface topography could be observed between the studied substrates. For example, fine fibrils overlapping each other as a layer of cellulose ribbons randomly oriented could be observed in the $\mathrm{CBC}$ micrograph, while the other substrates showed in general a more cohesive surface structure. These differences may also lead to a different biological response, since the biomaterial surface topography influences protein adsorption and subsequent biological responses. ${ }^{60}$ In the case of $\mathrm{ABC}$ substrates, changes in surface topography when compared to pristine $\mathrm{BC}$ were not expected, since it has been reported that the microfibrillar morphology of $\mathrm{BC}$ is maintained following acetylation. ${ }^{37}$ The close permeability behavior between BC samples suggests that the three 

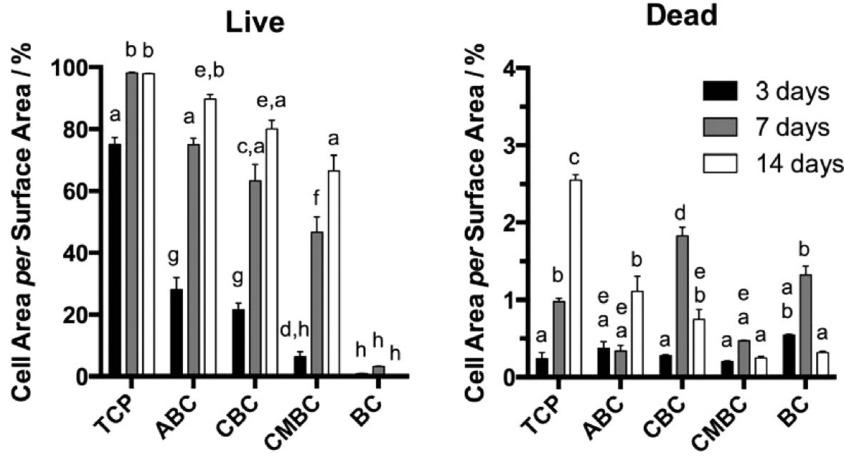

Figure 9. Data inferred from the LIVE/DEAD micrographs (Figure 8) regarding the surface area occupied by cells per total surface area. Left figure shows the area in \% occupied by live cells, whereas the righthand-side figure shows area in \% corresponding to dead cells. Six representative fields were used for each condition. The same letters are given to data not different statistically.

surface modification approaches may have affected only the superficial layer of BC fibers. Further work to evaluate the substrates physicochemical properties, as well as the bulk structural organization of the membranes is envisaged.

In RPE transplantation, biomaterial manipulation is required and it has to conform to the movements and available space of the surrounding tissue after transplantation. Therefore, structural stability (easy manipulation, no swelling nor degradation) and mechanical integrity (resistance to tear) are relevant features. ${ }^{61,62}$ After 12 weeks, all substrates showed no signs of degradation and were easily manipulated with tweezers. However, acetylated substrates were easier to manipulate due to a stiffer behavior, when compared to pristine and polysaccharide-adsorbed BC substrates that easily wrinkled. In this sense, $A B C$ substrates seemed to be the most appropriate for RPE transplantation, where the biomaterial manipulation for a correct positioning of ultrathin substrates in the subretinal space is vital for the success of the transplant procedure. ${ }^{7,14}$ However, some signs of swelling were observed and quantified (Figure 4). After 1 week, BC, CBC, and CMBC samples presented similar swelling profiles, between 3 and 4 times its dry mass in water, while $\mathrm{ABC}$ substrates showed at least a third of the swelling effect shown by the other substrates. Water swelling stabilized after 4 weeks in PBS solution in 5, 2, 6, and 8 times its dry mass for $\mathrm{BC}, \mathrm{ABC}, \mathrm{CBC}$, and $\mathrm{CMBC}$ substrates, respectively. $A B C$ samples showed the lowest swelling, with a 2fold increase in its dry mass. In contrast to polysaccharide adsorption, that increased swelling, $\mathrm{BC}$ acetylation led to a lower swelling effect, which is beneficial for the envisaged application.

Tensile strength $\left(\sigma_{\max }\right)$, elongation-at-break $\left(\varepsilon_{\text {break }}\right)$, and elastic modulus $(E)$ were obtained from the stress-strain assays performed in the tensile mode (Table S3, Figure 5). All samples showed similar stress-strain behavior, with stress increasing with strain increment until the sample collapse (Figure 5). Furthermore, $\mathrm{BC}$ and $\mathrm{ABC}$ samples showed the highest elastic modulus, but the latter exhibited a slightly smaller tensile strength and elongation at break as compared to pristine $\mathrm{BC}$ samples. This is correlated with a stiffer behavior, when manipulated, shown by the ABC substrates. Moreover, it was observed a 3-fold and 5-fold decrease in the elastic modulus, respectively, for similar tensile at break and an increase in the strain at break from $8 \%$ for neat $\mathrm{BC}$ to approximately 25 and $30 \%$ for $\mathrm{CBC}$ and CMBC substrates, respectively (Table S3).

Nanofibrous membranes of poly(lactic-co-glycolic acid) (PLGA) and collagen type I were likewise evaluated as potential BM substitutes. ${ }^{63}$ The values obtained for the PLGA nanofibrous membrane were $1.5 \pm 0.4 \mathrm{MPa}, 28.8 \pm$ $4.9 \%$, and $131.9 \pm 13.3 \mathrm{MPa}$, for maximum tensile strength, tensile strain, and elastic modulus, respectively. Also, higher values were obtained for the collagen nanofibrous membrane, with $10.8 \pm 0.7 \mathrm{MPa}, 70.0 \pm 4.6 \%$, and $217.9 \pm 15.3 \mathrm{MPa}$ for maximum tensile strength, tensile strain, and elastic modulus, respectively.

Since BC is a biomaterial produced by a Gram-negative bacterium, the presence of endotoxins, even following purification after fermentation, may constitute a problem when considering its use as an implantable material. The endotoxin levels measured in the sterile water incubated with $\mathrm{BC}$ substrates were $0.85 \pm 0.19,0.11 \pm 0.01,0.79 \pm 0.07$, and $0.67 \pm 0.18 \mathrm{EU} \cdot \mathrm{L}^{-1}$ for $\mathrm{BC}, \mathrm{ABC}, \mathrm{CBC}$, and $\mathrm{CMBC}$ substrates, respectively. These values are much lower than the established limits of $500 \mathrm{EU} \cdot \mathrm{L}^{-1}$ for general medical devices and of $60 \mathrm{EU}$. $\mathrm{L}^{-1}$ for devices that contact cerebrospinal fluid. ${ }^{64}$

These results show that the endotoxins were successfully removed during the washing procedures. Indeed, treatment of BC with $1 \mathrm{~N} \mathrm{NaOH}$ solution, followed by rinsing with deionized water, was found to be an effective purification/ depyrogenation method for thin BC scaffolds. ${ }^{25}$ On the other hand, the acetylation process showed an 8-fold decrease in the amount of endotoxins present. Bodin et al. ${ }^{25}$ obtained similar endotoxin values for their BC scaffolds (produced by G. xylinus, ATCC 700198). From the above, all BC substrates can be deemed as nonpyrogenic and should not induce complications in vivo.

Cell Viability and Proliferation. Cells were observed after 14 days of hTERT-RPE cell culture in the different BC substrates using SEM (Figure 6). Pristine BC substrates showed only residual cells adhering on the surface, in contrast to the modified $\mathrm{BC}$ substrates. The low cell adhesion and lack of cell proliferation in unmodified $\mathrm{BC}$ is in accordance with our previous works, where $\mathrm{BC}$ surface functionalization with proteins and nitrogen plasma modification were required to improve the cell interaction with the substrate. ${ }^{20,21} \mathrm{ABC}$ showed a surface nearly fully covered by a cell monolayer, followed by the $\mathrm{CBC}$ substrate, which performed similarly. The $\mathrm{CMBC}$ substrate required a longer period of time to obtain a cell monolayer covering the entire surface. The results suggest that the cells do not penetrate into the pores of BC substrates, but only adhere to the surface of the membrane. Indeed, the pore size is at least 20 -fold smaller as compared to the cells sizes. Cell ingrowth in hydrated BC samples has been observed; ${ }^{20}$ however, this phenomena only occurs in hydrated samples as nanofibers are further separated. BC drying causes the collapse of the $3 \mathrm{D}$ pore structure, thus approximating the fibers. These establish strong hydrogen bonds and a tighter network, hence, limiting the $\mathrm{BC}$ hydration capacity. Therefore, cell growth and proliferation occurs only at the membranes surface. Contrarily, a low cell culture media availability and the lack of contact with other cells would likely result in viability loss or even cell death.

The extent of cell adhesion play a decisive role in regulating the subsequent cell proliferation activity. ${ }^{52}$ Fluorescence microscopy and MTS assays were performed to assess cell viability and proliferation on the $\mathrm{BC}$ substrates and on tissue 
culture polystyrene (TCP) used as a control surface. Metabolic activity was measured after 3, 7, and 14 days (Figure 7) using the MTS assay.

Regarding the metabolic activity after 3 days in culture, a great difference in the number of adhered viable cells between the BC surfaces and the TCP control was observed (Figure 7). Cells cultured in the TCP surface apparently show some growth arrest after 7 days, since the same metabolic activity was observed for a prolonged culture (14 days), thus, indicating the presence of a confluent cell monolayer. Although, after 3 days, a lower number of cells adhered onto the modified $\mathrm{BC}$ substrates, as compared to those in TCP, they were able to further proliferate over prolonged culture times, of 7 and 14 days, as confirmed by an increase in the metabolic activity. After 14 days, $A B C$ substrates exhibited the closest metabolic activity values to the 7 day cultured cells in TCP. BC unmodified substrates showed only residual metabolic activity, indicating the reduced presence of adhered cells. The metabolic activity data is in accordance with SEM results after 14 days of culture (Figure 6).

To visualize the cell viability using the different $\mathrm{BC}$ substrates, LIVE/DEAD fluorescence images were taken (Figure 8). Surface area occupation with viable and dead cells was also quantified and further compared with the metabolic activity data (Figure 9), using the open source platform FIJI for LIVE/DEAD image analysis.

The LIVE/DEAD fluorescence micrographs (Figure 8) were coherent with the SEM visual observations. The LIVE/DEAD related cell quantification with FIJI (Figure 9) also corroborated the metabolic activity data. Additionally, these results indicated the occurrence of residual cell death in all BC substrates (below 3\%), with the highest value of cell death obtained in the TCP control after 14 days, which is explained by the occurrence of some cell overgrowth above the monolayer leading to a decreased availability of nutrients for the cells in the lower layer and consequently to cell death. Also, a surface nearly fully covered with viable cells was visualized for the TCP surface after 7 days and for ABC after 14 days, since viable cells cover almost $100 \%$ of the surface area. Acetylated substrates presented higher initial cell adhesion and similar proliferation rates comparing to the other modified $\mathrm{BC}$ substrates, as suggested by the results obtained in the cell viability (Figures 8 and 9) and metabolic activity (Figure 7) assays.

TCP (water contact angle of $20^{\circ}$ reported elsewhere ${ }^{58}$ ) and $\mathrm{BC}$ are both very hydrophilic. The surface roughness of BC seems to negatively affect cell adhesion and viability. $\mathrm{CBC}$ and CMBC, also hydrophilic (comparable to TCP and BC) showed a better adhesion and cell proliferation, which is probably associated with the presence of the chitosan and CMC functional groups. However, the presence of loose fibers at the $\mathrm{CBC}$ surface (Figure 3) apparently does not influence significantly the cells behavior in vitro. On the other hand, $A B C$, which is more hydrophobic, seems to be the substrate that promotes the highest cell adhesion and proliferation, with levels comparable to the TCP after 14 days. The effect of flat plasma polymer (PP) films with different chemical functionalities (amine, carboxyl, hydroxyl, and hydrocarbon) on RPE cell adhesion and growth has been reported. ${ }^{58}$ After 10 days of cell culture with the ARPE-19 immortalized cell line and primary human RPE cells, no statistically significant differences were observed between the different surfaces and the TCP positive control, except for the hydrophobic surface of hydrocarbon, which had almost no cell adhesion and proliferation.

A previous study has reported that RPE cells preferred smooth rather than rough surfaces. ${ }^{46} \mathrm{RPE}$ cell adhesion herein obtained with the modified BC substrates was lower than other substrates developed for the same purpose, where cells have reached confluence at the same time as the control surface (TCP or glass), ${ }^{12,14}$ due to a higher initial cell adhesion. Therefore, further BC substrate improvement is still required to achieve a better (faster) cell response. It has been reported that protein adsorption modifies the materials surface roughness by smoothing its irregularities. ${ }^{46}$ Hence, surface coating with relevant proteins for cell adhesion that can simulate the RPE natural environment, may be used to improve the cell response to the BC substrates developed in the current work. A similar strategy has been reported by other authors, namely through the adsorption of glycosaminoglycans on a polymerized allylamine/octadiene surface leading to an increased ARPE-19 proliferation. ${ }^{65}$ Nevertheless, although $\mathrm{BC}$ may present some surface roughness, we showed that cells were able to adhere and proliferate on the modified substrates. Also, we presented other $\mathrm{BC}$ properties that are interesting for the envisaged application. Therefore, the results gathered in this work suggest the potential of this biomaterial for the ultimate application of RPE transplantation.

\section{CONCLUSIONS}

The unique $\mathrm{BC}$ properties, including permeability to gas and fluid transport and stability, ease of manipulation (mechanical stability), and limited swelling, make it a potential substrate for the successful RPE transplantation. The current work highlights the feasibility of this substrate for the above-mentioned application. Data on surface wettability, energy, charge, swelling, stability, mechanical properties, amount of endotoxins detected, cell adhesion, and proliferation obtained for all the BC modified substrates studied herein indicate that the acetylated BC substrate is the most interesting. The bulk properties were found to be similar among all the substrates, which were porous, permeable up to $300 \mathrm{kDa}$, and dimensionally stable (particularly the $\mathrm{ABC}$ ones). Surface modifications allowed to addressing the low cell adhesion and lack of proliferation with unmodified $\mathrm{BC}$, with $\mathrm{ABC}$ showing increased initial cell adhesion and similar proliferation as compared to the other modified BC substrates.

To further validate the $\mathrm{BC}$ substrates as viable RPE cell carriers in retinal degenerative diseases, the evaluation of RPE function, morphology, and tissue reaction is required, particularly in the case of the acetylated BC substrates. Additionally, other surface modifications may be studied toward a better cell response, such as the adsorption of proteins that promote cell adhesion prior to cell culture. In summary, despite further surface improvements can still be designed, the results here presented are very promising when envisioning the ultimate use of $\mathrm{BC}$ substrates for $\mathrm{RPE}$ transplantation.

\section{ASSOCIATED CONTENT}

\section{S Supporting Information}

Table S1 shows the surface energy components of probe liquids used in contact angle measurements. Table S2 presents the measured apparent contact angles by each probe liquid and the calculated surface free energy components for each BC substrate. Tensile strength $\left(\sigma_{\max }\right)$, elongation-at-break $\left(\varepsilon_{\text {break }}\right)$, 
and elastic modulus $(E)$ for each substrate are shown in the Table S3. This material is available free of charge via the Internet at http://pubs.acs.org.

\section{AUTHOR INFORMATION}

\section{Corresponding Author}

*E-mail: 1rmr@deb.uminho.pt.

\section{Notes}

The authors declare no competing financial interest.

\section{ACKNOWLEDGMENTS}

The authors acknowledge the Portuguese Foundation for Science and Technology (FCT, Portugal) for the financial support provided by the Research Grants SFRH/BD/63578/ 2009, SFRH/BD/64901/2009, SFRH/BPD/64958/2009, and SFRH/BPD $/ 63148 / 2009$ for S.G., J.P., J.P.S., and V.S., respectively. The authors also acknowledge the Projects PEstOE/EQB/LA0004/2013, PEst-OE/EQB/LA0023/2013, PTDC/BBB-BQB/2450/2012, and RECI/BBB-EBI/0179/ 2012 (Number: FCOMP-01-0124-FEDER-027462), cofunded by QREN, FEDER.

\section{REFERENCES}

(1) Ambati, J.; Ambati, B. K.; Yoo, S. H.; Ianchulev, S.; Adamis, A. P. Surv. Ophthalmol. 2003, 48, 257-93.

(2) Binder, S.; Stanzel, B. V.; Krebs, I.; Glittenberg, C. Prog. Retinal Eye Res. 2007, 26, 516-54.

(3) Stanzel, B. V.; Binder, S. In Retinal Pharmacotherapy; Nguyen, Q. D., Rodrigues, E. B., Farah, M. E., Mieler, W. F., Eds.; Elsevier: New York, 2010; p 344.

(4) Lim, L. S.; Mitchell, P.; Seddon, J. M.; Holz, F. G.; Wong, T. Y. Lancet 2012, 379, 1728-38.

(5) Strauss, O. Physiol. Rev. 2005, 85, 845-81.

(6) Booij, J. C.; Baas, D. C.; Beisekeeva, J.; Gorgels, T. G. M. F.; Bergen, A. A. B. Prog. Retinal Eye Res. 2010, 29, 1-18.

(7) Julien, S.; Peters, T.; Ziemssen, F.; Arango-Gonzalez, B.; Beck, S.; Thielecke, H.; Büth, H.; Vlierberghe, S.; Sirova, M.; Rossmann, P.; Rihova, B.; Schacht, E.; Dubruel, P.; Zrenner, E.; Schraermeyer, U. Biomaterials 2011, 32, 3890-8.

(8) Miller, J. W. Am. J. Ophthalmol. 2013, 155, 1-35.

(9) da Cruz, L.; Chen, F. K.; Ahmado, A.; Greenwood, J.; Coffey, P. Prog. Retinal Eye Res. 2007, 26, 598-635.

(10) Liu, Z.; Yu, N.; Holz, F. G.; Yang, F.; Stanzel, B. V. Biomaterials 2014, 35, 2837-50.

(11) Carr, A. F.; Smart, M. J. K.; Ramsden, C. M.; Powner, M. B.; da Cruz, L.; Coffey, P. J. Trends Neurosci. 2013, 36, 385-95.

(12) Silva, G. R.; Silva-Cunha, A.; Vieira, L. C.; Silva, L. M.; Ayres, E.; Oréfice, R. L.; Fialho, S. L.; Saliba, J. B.; Behar-Cohen, F. J. Mater. Sci.: Mater. Med. 2013, 24, 1309-17.

(13) Treharne, A. J.; Thomson, H. A.; Grossel, M. C.; Lotery, A. J. J. Biomed. Mater. Res., Part A 2012, 100, 2358-64.

(14) Thumann, G.; Viethen, A.; Gaebler, A.; Walter, P.; Kaempf, S.; Johnen, S.; Salz, A. K. Biomaterials 2009, 30, 287-94.

(15) Klemm, D.; Schumann, D.; Udhardt, U.; Marsch, S. Prog. Polym. Sci. 2001, 26, 1561-603.

(16) Czaja, W. K.; Young, D. J.; Kawecki, M.; Brown, R. M. Biomacromolecules 2007, 8, 1-12.

(17) Fu, L.; Zhang, J.; Yang, G. Carbohydr. Polym. 2013, 92, 143242.

(18) Chang, C.; Zhang, L. Carbohydr. Polym. 2011, 84, 40-53.

(19) Bodin, A. Compr. Biomater. 2011, 2, 405-10.

(20) Andrade, F.; Costa, R.; Domingues, L.; Soares, R.; Gama, M. Acta Biomater. 2010, 6, 4034-41.

(21) Pertile, R. A. N.; Andrade, F. K.; Alves, C., Jr.; Gama, M. Carbohydr. Polym. 2010, 82, 692-8.
(22) Lin, W.; Lien, C.; Yeh, H.; Yu, C.; Hsu, S. Carbohydr. Polym. 2013, 94, 603-11.

(23) Scherner, M.; Reutter, S.; Klemm, D.; Sterner-Kock, A.; Guschlbauer, M.; Richter, T.; Langebartels, G.; Madershahian, N.; Wahlers, T.; Wippermann, J. J. Surg. Res. 2014, 189, 340-7.

(24) Bäckdahl, H.; Risberg, B.; Gatenholm, P. Mater. Sci. Eng., C 2011, 31, 14-21.

(25) Bodin, A.; Bharadwaj, S.; Wu, S.; Gatenholm, P.; Atala, A.; Zhang, Y. Biomaterials 2010, 31, 8889-901.

(26) Nimerskern, L.; Ávila, H. M.; Sundberg, J.; Gatenholm, P.; Mueller, R.; Stok, K. S. J. Mech. Behav. Biomed. Mater. 2013, 22, $12-$ 21.

(27) Zaborowska, M.; Bodin, A.; Bäckdahl, H.; Poppc, J.; Goldsteinc, A.; Gatenholm, P. Acta Biomater. 2010, 6, 2540-7.

(28) Wang, J.; Gao, C.; Zhang, Y.; Wan, Y. Mater. Sci. Eng., C 2010, $30,214-8$.

(29) Chang, C.; Zhang, L. Carbohydr. Polym. 2011, 84, 40-53.

(30) Pooyan, P.; Kim, I. T.; Jacob, K. I.; Tannenbaum, R.; Garmestani, H. Polymer 2013, 54, 2105-14.

(31) Kiilgaard, J. F.; Wiencke, A. K.; Scherfig, E.; Prause, J. U.; La, C. M. Acta Ophthalmol. Scand. 2002, 80, 76-81.

(32) Hsiue, G. H.; Lai, J. Y.; Lin, P. K. J. Biomed. Mater. Res. 2002, 61, $19-25$.

(33) Lee, C. J.; Huie, P.; Leng, T.; Peterman, M. C.; Marmor, M. F.; Blumenkranz, M. S.; Bent, S. F.; Fishman, H. A. Arch. Ophthalmol. 2002, 120, 1714-8.

(34) Lund, R. D.; Kwan, A. S.; Keegan, D. J.; Sauve, Y.; Coffey, P. J.; Lawrence, J. M. Prog. Retinal Eye Res. 2001, 20, 415-49.

(35) Lu, L.; Nyalakonda, K.; Kam, L.; Bizios, R.; Gopferich, A.; Mikos, A. G. Biomaterials 2001, 22, 291-7.

(36) Gullapalli, V. K.; Sugino, I. K.; Van, P. Y.; Shah, S.; Zarbin, M. A. Exp. Eye Res. 2005, 80, 235-48.

(37) Kim, D.; Nishiyama, Y.; Kuga, S. Cellulose 2002, 9, 361-7.

(38) Orelma, H.; Filpponen, I.; Johansson, L. S.; Laine, J.; Rojas, O. J. Biomacromolecules 2011, 12, 4311-8.

(39) Kujawa, J.; Rozicka, A.; Cerneaux, S.; Kujawski, W. Colloids Surf., A 2014, 443, 567-75.

(40) van Oss, C. J.; Giese, R. F. Clays Clay Miner. 1995, 43, 474-7.

(41) Zenkiewicz, M. JAMME 2007, 24, 137-45.

(42) Al-Turaif, H.; Bousfield, D. W. Prog. Org. Coat. 2004, 49, 62-8.

(43) Combe, E. C.; Owen, B. A.; Hodges, J. S. Dent. Mater. 2004, 20, 262-8.

(44) Lu, J. T.; Lee, C. J.; Bent, S. F.; Fishman, H. A.; Sabelman, E. E. Biomaterials 2007, 28, 1486-94.

(45) Rambhatla, L.; Chiu, C.; Glickman, R.; Rowe-Rendleman, C. Invest. Ophthalmol. Visual Sci. 2002, 43, 1622-30.

(46) Tezcaner, A.; Bugra, K.; Hasirci, V. Biomaterials 2003, 24, 4573-83.

(47) Arima, Y.; Iwata, H. Biomaterials 2007, 28, 3074-82.

(48) Lee, J. W.; Deng, F.; Yeomans, W. G.; Allen, A. L.; Gross, R. A.; Kaplan, D. L. Appl. Environ. Microbiol. 2001, 67, 3970-5.

(49) Hu, W.; Chen, S.; Xu, Q.; Wang, H. Carbohydr. Polym. 2011, 83, $1575-81$.

(50) Li, Z.; Ramay, H. R.; Hauch, K. D.; Xiao, D.; Zhang, M. Biomaterials 2005, 26, 3919-28.

(51) Grande, C.; Torres, F.; Gomez, C.; Bano, M. C. Acta Biomater. 2009, 5, 1605-15.

(52) Bacakova, L.; Filova, E.; Parizek, M.; Ruml, T.; Svorcik, V. Biotechnol. Adv. 2011, 29, 739-67.

(53) Ma, Z.; Mao, Z.; Gao, C. Colloids Surf., B 2007, 60, 137-57.

(54) Vogler, E. A. Biomaterials 2012, 33, 1201-37.

(55) Rüttermann, S.; Trellenkamp, T.; Bergmann, N.; Raab, W. H. M.; Ritter, H.; Janda, R. Acta Biomater. 2011, 7, 1160-5.

(56) Faucheux, N.; Schweiss, R.; Lützow, K.; Werner, C.; Groth, T. Biomaterials 2004, 25, 2721-30.

(57) Chen, H.; Song, W.; Zhou, F.; Wu, Z.; Huang, H.; Zhang, J.; Lin, Q.; Yang, B. Colloids Surf., B 2009, 71, 275-81.

(58) Kearns, V.; Mistry, A.; Mason, S.; Krishna, Y.; Sheridan, C.; Short, R.; Williams, R. L. J. Mater. Sci.: Mater. Med. 2012, 23, 2013-21. 
(59) Lu, B.; Zhu, D.; Hinton, D.; Humayun, M. S.; Tay, Y. C. Biomed. Microdevices 2012, 14, 659-67.

(60) Krishna, Y.; Sheridan, C. M.; Kent, D. L.; Grierson, I.; Williams, R. L. J. Biomed. Mater. Res., Part A 2006, 669-78.

(61) Machado, R.; Costa, A.; Sencadas, V.; Garcia-Arévalo, C.; Costa, C. M.; Padrão, J.; Gomes, A.; Lanceros-Méndez, S.; RodriguezCabello, J. C.; Casal, M. Biomed. Mater. 2013, 8, 065009.

(62) Thomson, R. C.; Giordano, G. G.; Collier, J. H.; Ishaug, S. L.; Mikos, A. G.; Lahiri-Munir, D.; Garcia, C. A. Biomaterials 1996, 17, $321-7$.

(63) Warnke, P.; Alamein, M.; Skabo, S.; Stephens, S.; Bourke, R.; Heiner, P.; Liu, Q. Acta Biomater. 2013, 9, 9414-22.

(64) Guideline on validation of the limulus amebocyte lysate test as an end-product endotoxin test for human and animal parenteral drugs, biological products and medical devices; U.S. Department of Health and Human Services, Public Health Service, Food and Drug Administration: Rockville, MD, 1987; p 49.

(65) Zuber, A. A.; Robinson, D. E.; Short, R. D.; Steele, D. A.; Whittle, J. D. J. Mater. Sci.: Mater. Med. 2014, 25, 1367-73. 